Studies in African Linguistics

Volume 20, Number 2, August 1989

\title{
SILENCE AND RITUAL RESPONSE IN IGBO DISCOURSE
}

\author{
Bertram A. Okolo \\ University of Benin
}

\begin{abstract}
This study discusses silence and ritual response as behavioural acts that are communicatively significant among the Igbos of Nigeria. Using actual discourse samples, the appropriate and inappropriate uses of these acts as well as their functions are highlighted.
\end{abstract}

\section{Introduction}

In the Igbo culture, as may be the case in most other cultures, verbal communication is regarded as the core of any message among interactants in a conversation. However, it should be remembered that a characteristic of human speech is that most verbal behaviours, especially in Igbo culture, are usually accompanied by silence, bodily movements (most noticeably of the arms and hands as in gestures and gesticulations) and by facial expressions (as when a person's demeanor is determined through facial contortions, etc.). Of all these three accompaniments of verbal behaviours, bodily movements and facial expressions seem to have been more recognized as communicative acts than silence. For example, it has been substantiated in the literature that arm and hand movements and, to a certain extent, facial expressions are intimately linked with the process of speech production in such a way that they are rhythmically timed with speech and often seen to reflect the meaning which the speech expresses (cf. Goldman-Eisler [1958], Henderson et al. [1966], Butterworth and Beatie [1978], among others). Even at this, these bodily movements and facial expressions are merely regarded as having interpretive or relational metacommunicative significance rather than denotative (literal content level) significance which only verbal behaviour possesses.

However, it is my belief that non-verbal acts can equally be assigned denotative significance at any level depending on the contexts in which they occur, although 
their interpretive metacommunicative significance may remain limited to situations when they accompany speech. The assumption that they lack the denotative level of meaning lies in the fact that we tend to view the denotative level as being identical with and tied to verbai ieiraviour. In actual fact, this is not always the case because denotative does not necessarily imply that the literal content of a message must be clearly translated into linguistic symbols. This is because there exist some communicative acts which can be assigned derotative significance that cannot be clearly translated into language, but whic.., in some ways, manifest literal contents. For example, let's assume that you walk into an office where two people, say, Obi and Uche, are conversing. You say, "Hello," to both of them, but Uche pointedly ignores your greeting. Uche's failure to repond to your greeting can be assigned significance at a literal level (which is, nevertheless, difficult to transcribe) especially if considered in relation to the ongoing conversation, or in relation to other interpretive metacommunicative behaviours such as shoulder shrug or raised eyebrows.

Whatever be the case, it is interesting to note that there seems to be agreement as to the fundamental unity between verbal and non-verbal aspects of interpersonal communication. In other words, the distinctions often made between verbal and non-verbal communication is primarily artificial since every other verbal act contains non-verbal aspects which equally contribute to the meaning of the verbal act.

In this paper, it is my intention to examine these two behavioural acts, "silence" and "ritual response", which I consider communicatively significant among the Igbos of Nigeria. I shall discuss the appropriate and inappropriate uses of these acts in spontaneous conversational exchanges, their functional uses, and the way interactants manipulate them for greater communicative effects. It is hoped that this study will not only help to show that these acts are communicatively crucial in cultures where they obtain, but will also stimulate more detailed studies of the part played by these acts in various cultures for a better understanding of natural language discourses.

\section{Theoretical Background}

The recognition of the part played by silence in communication is not new. What seems to be new is crosscultural and crossdisciplinary study of silence. Basso [1970] to my knowledge seems to have pioneered a crosscultural investigation in this direction in his study of the use of silence among Western Apache inhabitants. Since then, interest in the role of silence in communication has blossomed, culminating in the publication of an insightful crosscultural and crossdisciplinary collection of articles on silence by Tannen and Saville-Troike [1985]. This volume not only enriches our understanding of silence as a communicative behaviour, but also highlights a variety of approaches to silence. As this book is 
at the moment an important and the only comprehensive work on silence, I shall try to summarize the various contributions presented in it.

The book, Perspectives on Silence, is divided into five parts with a common aim: "to heighten awareness of this universal aspect of human behaviour while at the same time emphasizing its complex nature as a cultural phenomenon and its richness as a research site" (p. xi). In the first part of the book, Saville-Troike presents an overview of what silence is, its types and functions, and goes on to make interesting distinctions between types of silence behaviours such as silence implying the absence of sound with no communication taking place versus silence that is communicative; verbal silence versus non-verbal silence; and meaningful silence without any propositional content versus silence that depends on adjacent utterances.

In the second part of the book, pausing and hesitation are discussed. In the presentation of this ethnographic investigation on attitudes toward silence among Athapaskan Indians, Ron Scollon observes that pauses are assigned communicative significance by members of the cultural group. Wallace Chafe in his observations based on the viewing of a film, examines the reasons for hesitation, and contends that hesitation corresponds to the act of creation in narratives. Anne Graffam Walker, picking on a courtroom scene, discusses the opposing interpretations of witness hesitancy and the effects of hesitations by witnesses on lawyer's impressions.

The third part of the book concentrates on the uses and meanings of silence, and examines the interpretation and evaluation of silence behaviour in specific situations. For example, Deborah Tannen takes a look at the conversational style of New York Jews as interpreted by non-Jewish Californians during a dinner party, Daniel Maltz contrasts the role of noise in Pentecostal worship with the role of silence among Quakers, and Perry Gilmore examines a classroom situation and contrasts students' and teachers' interpretation and uses of silence.

Part four of the book is devoted to crosscultural perspectives of silence. First, George Saunders presents the view that noise and "grim silence" are equivalent to emotional management by the Italians. Then, Gregory Nwoye discusses the significance of silence among the Igbos of Nigeria, and concludes that in the Igbo culture, silence is eloquent. (As this paper is relevant to this study, I shall take it up in greater detail later). In another crosscultural investigation, Jaakko Lehtonen and Kari Sajavaara mention that among the Finns, preference for silence may be historically correlated to settlement patterns.

The final part of the book deals with silence and nonverbal communication. Two important contributions in this section include Sue Philips' article which contrasts interaction structured through silence and that structured through talk, and Adam Kendon's article which examines the use of gesture in face-to-face interaction in everyday situations.

Although the volume is a "Bible" on silence because of the quality of the contributions, there seems to be an obvious gap that needs to be filled. In most of the 
contributions, and as noted by Goldsien [1987:567] in her review of the book, "There is unfortunate insufficiency of contextual information, matching scant pieces of social data with larger pieces of linguistic data." This gap forces the reader to rely solely on the autlor as to which uses and interpretation of silence are significant in given situations. This brings out the fact that attitudes toward silence may be dependent on a variety of cultural and situational constraints and influences. The intention of this paper is to attempt to provide these constraints in the use of silence and ritual responses as observed among the Igbos. It is hoped that this work will generate more research on this topic.

\section{Silence and Ritual Response as Communicative Acts}

That silence and ritual response are communicatively significant behavioural acts will be obvious if we reflect for a moment on the roles they play in our everyday conversations: they hurt, they work against the development of a healthy interaction, as well as promote interpersonal communication if employed constructively in appropriate contexts.

A dictionary definition of "silence" may include such meanings as "absence of any sound or noise", "stillness", or "forbearance of speech or utterance". In conversations, I will regard "silence" as the avoidance of linguistic or non-linguistic (non-linguistic used here according to general usage) behavioural act when verbal or non-verbal interaction with a conversational partner is expected. Since ritual response is a verbal behavioural act, $l$ will first try to argue that "silence" is a behavioural act, although whatever arguments presented here in favour of "silence" also apply to ritual response.

Being silent is an act, and in fact, can be regarded as a gesture. If gestures are regarded as acts that occur within a field of mutual perception among members of a cultural group, then they are best seen. not as isolated events that communicate something about a person, concept or an idea, but as part of an ongoing conversational exchange or transaction in which participants exist in relationship to each other. In other words, gestures include, not only what we do, but also what we fail to do. Not doing something is itself an act to which significance can be assigned [Watzlawick et al. 1967]. It therefore follows that silence, when employed within an ongoing communicative transaction may be a significant act in that context.

The implication arising from this is that it is impossible for one not to act in any conversational exchange, since every act becomes part of the context in the ongoing exchange. It should be borne in mind that it is not really crucial that both participants assign significance to an act for that act to affect the conversation. For example, consider a situation where a son is talking to his father on the need for an increase in his maintenance allowance at school, and the father remains silent. The son notices the silence and may interpret it to mean refusal, frugality, or an irresponsibility on his part in not being able to manage the little 
he is given in the face of the current economic difficulties. In this case, the fact that the son observed and assigned significance to the silence is more important than whatever the intentions of the father were in being silent. Thus, significance can be assigned to silence either in an experiential way (as when it contributes to the interpretation of a message) or in a behavioural way (as when a conversational partner responds to it in a predictable patterned way). Therefore, conversational partners need not be able to interpret a particular "silence" correctly or in the same way for it to be significant, since significance can be assigned to it whether or not the intentions of the actor are easily accessible. It therefore follows that participants can assign implicit or explicit significance to silence in a particular context. Explicit significance takes place when at least one of the participants consciously perceives and interprets the act.

Ritual response, like silence, is a significant act both at the denotative and interpretive levels. Here, I am using "ritual response" to refer to a verbal behavioural act that is formulaic in nature, which is deliberately employed by conversational partners either to avoid real or entirely honest interaction, or to promote an ongoing conversation. Ritual response as implied here is an extremely shallow conversation that is highly formalized and formulaic in character, employed by interactants in such a way that it affects the ongoing conversation. It is therefore a verbal behavioural act, which, like silence, can be assigned significance in a communicative encounter.

It is important to note that silence and ritual response could be positively and negatively used. If positively used, they not only promote healthy interactions, but also strengthen bonds of friendship and love. For example, imagine what happens when you run into an old friend of yours with whom you have been out of touch for years. As you probably embrace each other, there is usually that wonderful silence and ritual responses that reaffirm or confirm your commitments and love to each other. On the other hand, when used negatively, rather than promote acceptance and trust, they push interactants further apart.

Among the Igbos, these behavioural acts are strategically employed in interpersonal communication. In the next section I intend to show, through reconstructed, transcribed, tape-recorded, and observed face-to-face interactions, how communicatively significant they are in Igbo culture.

\section{Silence in Igbo Discourse}

As a communicative act, silence is both an environment in which we grow and also an instrument which we can strategically manipulate in discourses [Smith \& Williamson 1977]. When considered as an environment, silence becomes an act to which members of a cultural group collectively assign specific kinds of significance when it occurs within on-going interactions. As an instrument, we are looking at the way participants employ silence in discourses to which at least one 
partner has assigned significance in a particular conversational setting. It is the instrumental aspect of silence that I am interested in here.

Just as every child in the Igbo-speaking area learns to speak fluent Igbo, so every member of the Igbo cultural group learns how to act, how to respond to acts, and how to interpret acts in ways that are more or less recognizable within the culture. In other words, within the concept of Igbo culture, we learn how to behave, how and what to discriminate, and how to assign significance to behavioural acts. Thus, significance is, in general, determined by culture; meaning, however, is created on several levels by participants in a transaction.

Nwoye [1985] observes quite correctly that the Igbos are known for their talkativeness. Whether in the company of relations, friends, or even total strangers, there is always that inner drive in the majority of them to talk, not necessarily to communicate something, but primarily as a "filler" for interactional silence. As Nwoye puts it, "it is against this background of ebulient loquacity and vivacity that the ominous meaning of silence among the Igbo can be interpreted. For a people with this type of disposition, silence is a highly marked form of behaviour" (p. 185).

He further goes on to discuss three major aspects of silence among the Igbos: the institutionalized silence, group determined silence, and individually negotiated silence. In institutionalized contexts as in bereavement or ritual performances, silence is mandatory. It therefore follows that any violation of this expected form of behaviour in such situations may attract some suspicion or lead to the inefficacy of the ritual being performed. Group determined silence is a very effective way of instilling discipline and compliance on a culprit who violates some societal norms. When this happens, members of the society are forbidden to talk to, visit, or trade with the culprit and the family until the "sins" are expiated. Individually negotiated silence among the Igbos does not differ markedly from what obtains in most other cultures. For example, it is common to find across cultures people who avoid talking to their enemies, people they don't like, or even strangers. In such situations, silence might be used negatively to communicate anger, envy, dislike, distrust, or it might even mean a pausing posture to enable one to reorganize and come up with a better revenge strategy, akin to what Nwoye [1985] calls "deferred action".

Individuals can equally use silence positively to mean consent or approval, or to express that inner satisfaction and fulfilment that cannot be sufficiently expressed in words. In this paper it is my intention to explore further the significance of silence among the Igbos drawing from actual conversational samples.

Traditional Igbo society used to be polygamous in character. In the past, wealth and greatness were assessed, not necessarily in terms of one's investments or huge financial deposits in some banks, but in terms of the number of wives and children one was able to maintain and also the amount of the consequent bickerings one was able to contain and absorb. My maternal grandfather has three wives. At the last New Yam festival to which I was invited, the celebration was 
almost marred by a quarrel which erupted between the eldest and the youngest wives over whose turn it was to clean the compound. Both of them rushed to my grandfather to state their cases. The following communication took place: 1

1st Wife: Ogbuefi, $j$ hugo otu nwunye di $m$ si acho nke $m$ ga-ekwu? $O$ makwa na obu ya nwe izacha ezi n'izu a, ma o mee anya ka o hughi ya. Nza ubochi ato mmadu emetubeghi aziza n'ezi a. I hụkwuru ya. Ya ka m na- agwa ya n'ututu, o wee chiri onu ghaa $m$.

'Ogbuefi (title name), do you see how my co-mate is looking for what I would say? She knows it is her turn to clean the compound this week, but she pretends as if she doesn't see the dirtiness of the whole place. For three consecutive days now, nobody has touched broom on this compound. You saw it yourself. That was what I was telling her in the morning and she opened her mouth at me.'

3rd Wife: Okpe ikpe, $i$ kpesigo? Ugbo ole ka i zara ya n'izu gara aga? $O$ nwere ihe $m$ gwara gi? $O$ wee buru iza ezi ka $i g a-e j i ~ k p o ~ m$ iru uttuttu.

'Reporter, have you finished reporting? How many times did you sweep it last week? Did I tell you anything? And it is sweeping the compound that you are confronting me with first thing this morning.'

Ogbuefi: (Silent)

1st Wife: Ogbuefi, o kwa i nuru ihe 9 na-ekwu? $O$-kwa ihe o ga-asi na m kwuru ka o na-achọ? I gaghi atunye onu n'okwu a?

'Ogbuefi, I hope you heard what she said? Is it not to claim that I said so and so that she is looking for? Will you not say something in this matter?'

Ogbuefi: (Silent)

3rd Wife: Onye buru üzo chọwa ibe ya? Oburu na i hughizi ebe i ga-azodo ukwụ, were aziza zawa ezi. (walks away)

\footnotetext{
1This exchange (as many others used in this study) was reconstructed and transcribed in my field note-book. There are problems associated with carrying about tape-recorders. Apart from causing embarrassment, the sight of a tape-recorder may cause interlocutors to produce unrealistic samples since they would be aware that their utterances are being recorded. In spite of the pitfalls of reconstructing utterances, I find it equally illuminating as long as one is careful in using this procedure.
} 
'Who started looking for the other's trouble first? If you can't find where to step your feet, pick up a broom and sweep the compound.' (walks away)

Ogbuefi: (Silent)

1st Wife: I kwuzina okwu. (talking to the husband) Obury $m$ ugbua, i hy ihe $i$ ga-ekwu. (walks away)

'Keep silent. If it is me now, you will find what to say.' (walks away)

In this encounter, my grandfather turned deaf ears to all the complaints, and this probably made the first wife walk away angrily. Among the possible interpretations one can assign to my grandfather's act, the one that best reflects his intention is neutrality, for, as he remarked after the women had left, "Involve yourself in women's matters, and you will die before your time." The problem with this type of neutrality is that it sometimes appears to be the same as disinterest. It may be looked upon (as the 1st wife probably concluded) as deliberately ignoring the faults of the "loved one" to the exclusion of others. Such communication with "low effect" (as Gibb [1961] calls it) sometimes communicates "not caring" for the welfare of others.

The above example, however, differs from a situation where silence communicates rejection. The segment below is taken from a tape-recorded conversation between four friends (cf. Okolo [1987]). I had invited the subjects in my office to take part in a linguistic project. I bought some snacks and soft drinks for them, and told them that they would have to wait for some few minutes while I went to collect the questionnaires from the typist. The tape-recorder was left on without their knowledge. I came back after thirty-five minutes and their taperecorded conversations were transcribed. The fragment below is a part of their conversation. The subjects, however, were later told that the tape-recorded conversation would be used for a study.

One of the interactants was trying to reveal the other partner's sexual exploits in the presence of others, a topic the culprit probably did not intend to be made public. Thus the aggrieved partner turned deaf ears to all prying questions on details:

Subject 3: Dianyi, ${ }^{2}$ obu ebe ahụ ka i butere nwata i menyere egwu unyahury?

'(Regulator) Was that the place you picked the girl you showed pepper yesterday?'

\footnotetext{
2"Regulators" are used here to refer to words that are empty in content, but which serve as "introducers" in conversational exchanges. They usually signal commencement of conversation.
} 
Subject 1: (Silent)

Subject 2: (calls subject 1 by name) Kedu otu nwata di? 'How was the girl?'

Subject 1: (Silent)

Subject 4: Nna, i choghi inye anyi details?

'(Regulator) Don't you want to give us details?'

Subject 1: (Silent)

Subject 3: Kedu onye ma oge bank ji emechi?

'Who knows when the banks close?'

Subject 4: $O$ dikwa m ka obụ 1 o'clock.

'I think it is one o'clock.'

In this example, silence, which communicates rejection, seems to have been responsible for the discontinuation of the original topic, necessitating the introduction of a new topic. The significance of silence in this encounter will be better appreciated if we realize that the four interactants had all along been talking freely when suddenly the offending topic came up. Every attempt to make Speaker 1 contribute to the discussion failed, and the other participants rightly interpreted it as rejection, hence they abandoned the topic and switched to something else.

In discourses, being silent can communicate anger, especially when a participant bears the other a grudge. One of my students, (whom I will refer to as Jimmy), was consulting with me in my office when a friend of his, another student, Sam, entered. The following transcribed exchange took place (B stands for my name):

Sam: Good morning, Sir!

B: Good morning. Kedu? Unu na-agụkwa?

'Good morning. How are you? Are you studying?'

Sam: $\quad$ di mma. A na-anwa.

'I am fine. We are trying.' 
Sam: Jimmy, oteela m chọbalụ gi. Amaghi m na ọbu ebea ka i nọ.

'Jimmy, I have been looking for you for long. I did not know you are here.'

Jimmy: (Silent)

Sam: Anyi ga-ejezikwa na bookshop icho akwụkwo ahụ?

'Shall we still go to look for that book in the bookshop?'

Jimmy: (Silent)

Sam: Jimmy, oburogi ka m na-agwa? I naghi ekwuzi okwu?

'Jimmy, am I not talking to you? Don't you talk again?'

Jimmy: (Silent)

B: Jimmy, he is talking to you!

Jimmy: Sir, I know.

Sam: Sir, ka m puwagodu. Thank you, Sir.

'Sir, let me leave for now. Thank you, Sir.'

B: $\quad$ OK. I see you later.

After Sam had left, I asked Jimmy why he refused to respond to Sam's statements and questions. He told me that another friend of his had told him that Sam had said all sorts of things about him in the hostel, and that he felt very angry when he heard them. He went on to say that on the basis of what he heard, he didn't want to talk to Sam again, and that if Sam could say such things about him, he (Sam) could equally do him greater harm. Thus, by being silent, Jimmy was communicating anger which, of course, might not be obvious to Sam at the time, depending on whether or not he suspected that Jimmy may have heard what he allegedly said about him.

On the other hand, silence can also communicate agreement. My uncle's son, Chidi, aged eleven, had won the sum of fifty Naira in a soft drink competition. He came back to show us the money and to itemize what he was going to do with the winning. The following is a reconstructed version of the exchange: 
Chidi: Daddy, lee ego $m$ winili na Sprite. Fifty Naira!

'Daddy, this is the money I won in the Sprite (competition). Fifty Naira!'

Father: You see, ego ụgwo akwụkwo gi adigo.

'You see, the money for your school fees is now available'

Chidi: I si ego ugwo akwụkwọ? Aga m eji ya golu ihe.

'Do you say school fees? I shall use it to buy something.'

Father: Gini ka i ji ego? Jee nye mama gi ka o dobere gi.

'What are you buying with it? Go and give it to your mother to keep for you.'

Chidi: Daddy, m ga-eji ya go slippers na akwa P.E. na bolu m yọbaly gi nza ka i gotalum.

'Daddy, I will buy slippers with it and my Physical Education outfit and the ball I have been begging you since to buy for me.'

Father: (Silent)

Chidi: I ga egotalu $m$ ihe ndia ma $m$ dobe ya?

'Will you buy these things for me if I keep it?'

Father: (Silent)

Chidi: $A h$ ?

Father: (Silent)

Chidi: (Walks away)

In this example, the father's silence signifies approval, for, as he commented after the boy left, he gave in because the boy intended to spend the money usefully.

Consider another situation where silence communicates admission of guilt. My nephew, a boy of thirteen, had come back from school, went into the kitchen and ate up all the food meant for him and the elder sister. The mother confronted him: 
Mother: Emmanuel, kedu ihe mere nri $m$ dobeere gi na Chinwe?

'Emmanuel, what happened to the food reserved for you and Chinwe?'

Emmanuel: (Silent)

Mother: $\quad$ o kwa gi ka m na-aju?

'Is it not you I am asking?'

Emmanuel: (Silent)

Mother: $\quad$ - - - iri nri ka i na-ahy ike. Irie nke gi irie nke nwa nne gi maka na obu sọso gi ka agụu na-agu. Mekwa ya ozo ka m bee gi nti.

'It is only in eating food that you have strength. You eat yours and eat your sister's because you are the only person who feels hungry. Do that again and I will cut off your ear.'

Although the society considers it disrespectful for a younger person to keep mute when he is being addressed by an elder, this example is appropriate and in accord with societal norms where silence communicates admission of guilt.

Silence can communicate disagreement as exemplified in the fragment below. I travelled home for Easter, and on Easter eve, I decided to pay a courtesy call on my paternal uncle. On entering the house, I discovered that he was having a serious discussion with his son. He invited me to sit down and partake of the discussion since I was no stranger. The following exchange is a reconstructed and transcribed version of the discussion.

Son: $\quad$ Papa, I really love this girl. Soso ya bu onye m ma mụ na ya ga-ebini. Biko, kwadozienu. The problem bu na i mataghi onye o bu nke oma, otherwise, iga-ahu na $Q$ by ezigbo mmadu.

'Daddy, I really love this girl. She is the only person I can live with. Please, support (the marriage). The problem is that you don't understand her very well, otherwise, you will see that she is a nice person.'

Father: (Silent)

Son: Akowagolu $m$ gi ihe a otutu ugbo. Oburu na mu alughi Nkem, malu na onweghi onye obulla m ga-alu.

'I have tried to explain this to you several times. If I don't marry Nkem, know that I am not going to marry anybody else.' (walks away) 
I asked the father why he was objecting to a marriage that I believed was motivated by love. The father stated that on several occasions he had tried to explain to the son that the girl in question comes from a bad family. The girl's grandfather had committed all sorts of heinous acts in the past and that he wouldn't want to be associated with such a family. He further said that his son had insisted that those past acts didn't matter, but they do in the long run, he argued. Here, the father's silence sort of says "Go ahead and do what you wish, but you will not get my support."

The above examples illustrate the appropriate uses of silence. Like all other verbal behaviours, silence can be inappropriately used. In the following example, a friend of mine had asked his younger brother, a first year undergraduate student, to mow the lawn and trim the flower hedges. When we returned in the evening, none of these chores was done. My friend (A) confronted his brother:

A: Tom, ogini ka m gwara gi mee tutu anyi apuwa?

'Tom, what did I ask you to do before we left?'

Tom: (Silent)

A: $\quad$ O kwa mmadu ka m na-aju?

'Is it not somebody I am asking?'

Tom: (Silent)

A: Ya bu na anyi aburugo ogbo nke $m$ na-agwa gi okwu i gbachi $m$ nkiti?

'That is we have become age-mates, that when I am talking to you you keep silent?'

Tom: (Silent)

A: (Becomes infuriated and reaches for a cane but I restrain him.)

As I mentioned above, the society does not condone this type of silence since it is tantamount to ignoring the elder. No wonder my friend reached for a cane to demonstrate his resentment. In situations of this type, bidirectional uses of silence are unacceptable and frowned upon, and may be seen as communicating indifference. If Tom employed it here to mean unwillingness to perform the chores assigned to him (in which case it becomes admission of guilt), he really does not have any alternative since asserting his unwillingness verbally would 
have been more foolhardy. But if he had other reasons for not performing the chores, it is expected of him to mention them rather than keeping silent.

Another inappropriate use of silence which differs remarkably from the above example is its use as an "escape" or "hiding" mechanism. I am regarding this use as inappropriate in the sense that it not only works against the development of one's healthy self-concept, but it is also usually interpreted by others as indifference or unwillingness to relate (which may not be in agreement with the actor's intentions), and more often than not, people react to it by rejecting the silent individual.

Individuals can be unnecessarily shy in the company of others. This shyness could be as a result of several factors ranging from the level of education or sophistication to a feeling of inferiority, and any of these can drive one into "hiding" in silence. I attended a send-off party of one of my colleagues with a friend. My friend tried to strike up a conversation with a girl (P) who was sitting by him:

F: Nne, kedu?

'(Regulator) How are you?'

P: Good evening, Sir.

F: Good evening. Kedu aha gi?

'Good evening. What is your name?'

P: (Looks $\mathrm{F}$ in the face timidly)

F: Kedu aha gi? I bu nwanne George? (chief host)

'What is your name? Are you a sister to George?'

P: (Silent)

F: Nne, o nwere ihe na-esere anyi igaghi eji ghe $m$ onụ? Obụ igwa $m$ aha gi mma gi agwu? Aha m bu Felix.

'(Regulator) Are we quarrelling as to make you not talk to me? If you tell me your name will your beauty vanish? My name is Felix.'

P: (Gets up and changes seat)

F, totally embarrassed, quietly put down the cup of beer he was sipping. Since I overheard every bit of the exchange, I tried to convince him to ignore the whole incident so that it would not spoil the evening for him. But still, his coun- 
tenance betrayed the inner disappointment. The chief host noticed F's unusual quietness and came over to enquire if everything was all right. F narrated the incident to him, and George, in his usual humorous way, started teasing F. However, in a more serious note, George explained that $\mathrm{P}$ was his half sister and that he was not surprised that she behaved the way she did. He further explained that she had a problem in relating to people and that it was this problem that made him bring her out from the village to live with him.

Here, we see a case where silence is not really indifference on the part of the actor but inability to relate to others. Such individuals may, in fact, desire companionship, but their fear of exposing themselves forces them to keep mute. If explanations had not been given of P's problems, we would have interpreted her silence as indifference, thus rejecting her as a person. This example also illustrates another use of silence: a show of discomfort or embarrassment as demonstrated by F's putting down his beer and remaining quiet, thus attracting his host's attention.

From these examples it becomes clear that silence as a communicative act among the Igbos can be assigned significance in the context of an on-going conversation, whether or not the significance is in accord with the actor's real intentions. Since members of a particular cultural group act and respond to acts in predictable patterned ways, it follows that behavioural acts are interpretable in the context of any conversational exchange, and these acts can be appropriately or inappropriately employed in line with established cultural norms.

\section{Ritual Response in Igbo Discourse}

Ritualized communication is a behavioural act that is common in Igbo discourse. It can promote and facilitate an on-going communication as well as inhibit it, depending on when and how it is used.

Like silence, one can use ritualized responses to avoid all real and honest communication. In the segment below, I telephoned a friend to share the good news of the approved increase in our monthly pay, a topic I thought would generate excitement. The following reconstructed conversation took place (B stands for my name, and $\mathrm{R}$ for my friend's):

B: Nna, inugo na ha emego approve ego anyi na e-demand?

'(Regulator) Did you hear that they have approved the money we were demanding?’

\section{R: Eziokwu?}

'True?' 
B: A nụrụ m ya na News n'ụtutụ. Ha si na ha ga-ebido ikwu ya n'onwa a. 'I heard it in the Morning News. They said they would start paying it this month.'

R: Eh-e!

B: Ha biko kwụ ya, na ihe chere mmady erika.

'Let them please pay it, because the problems awaiting one are much.'

$\mathrm{R}$ : Ka a na-ele ha anya.

'Let's be watching them.'

B: I na-emezi ka ilaikighi ya.

'You are doing as if you don't like it.'

$\mathrm{R}$ : O ka m mee gini?

'What do you expect me to do?'

In this example, apart from shortening what would have been a lengthened and exciting conversation, formulaic responses as used by $\mathrm{R}$ not only made me feel bad for initiating the topic, but also implicates that he was "hiding" in ritual. Among the several possible interpretations for his acts may be lack of interest in the topic, unwillingness to be frank with me, or even an attempt to avoid being himself. Whatever R's intentions were in acting as he did, he succeeded not only in frustrating and subduing the ongoing conversation, but also in hurting the conversational partner whose enthusiasm in sharing something very important was dashed by R's shallow responses.

Thus, ritualized verbal acts can communicate "not caring" or indifference. In such situations, rather than being silent or assertive, the individual chooses to be "courteous" by hiding in ritual which provides him an opportunity to camouflage his actual intentions or feelings. Being silent would be more revealing of the actor's inner feelings, but ritual responses apart from shielding these inner feelings from the conversational partner, affords the actor the lee-way of criticizing whatever interpretations the hearer might come up with.

A more common and frequent use of ritual response is to communicate surprise or wonder, especially if one is hearing something for the first time. In the following example, a colleague of mine was telling me of how one of the clerks in the university was run down by a car and had her legs shattered ( $G$ stands for my friend's name and $\mathrm{B}$ for mine): 
G: I jego hu Mrs O na hospital?

'Have you gone to see Mrs. O. in the hospital?'

B: $O$ gini mere ya?

'What happened to her?'

G: I nuro na moto egbusigo ya na Saturday?

'Didn't you hear that she was almost killed by a car on Saturday?'

B: Eh-e! Eziokwu? Anụghikwa m.

'Eh-e! Truly? I didn't hear.'

G: $O$ no na main road na-eche taxi o ga-e ji je ahja. Ebe ahụ ka o kwy otu moto wee bia kutuo ya n'ala.

'She was standing by the main road waiting for a taxi to take her to the market. She was standing there when a car came and knocked her down.'

B: $O$-o nke melụnụ?

'Was that what happened?'

G: O kwa otu o ka esi wee nwu, rapu umu-aka ano.

'That's how she would have died, leaving four children behind.'

B: Chukwu alụkakwa. M ga-e je ihu ya.

'God has done well. I shall go to see her.'

The above example illustrates a sincere and an appropriate use of ritual responses, where the literal content of the expressions represents the speaker's intentions.

However, there are situations where ritual responses are strategically used to communicate doubt or disbelief. When used in this manner, the formulaic responses are really not sincere in the sense of either promoting the ongoing conversation or indicating a desire to learn more about what is being said, but merely euphemistic ways of expressing doubt or disbelief without inhibiting the conversation. Such usages, in fact, represent the direct opposite of the literal content of the expressions. An example of this usage is seen in this segment where Speaker 2 had invited Speaker 1 to join them in a business deal. Speaker 1 suspecting the deal to be dubious, declined, and Speaker 2 was forced to look for a more cooperative friend. The friend with whom Speaker 2 had suffered the 
business failure earlier (before the rcconstructed encounter below) confided in Speaker 1 of the disastrous failure of the deal. When Speaker 1 met Speaker 2, the business deal issue was raised:

Speaker 1: Uny emezikwalu business obụ?

'Did you (plural) still do the business?'

Speaker 2: Ofyma ofuma. O-o ihe ni na-agwa gi ka ; soro mee. Uru putara na ya ka nku.

'Very well. That was what I was telling you to do with us. The profit realized from it was much.'

Speaker 1: Eh-e! Gwa m okwu.

'Eh-e! Tell me something.'

Speaker 2: Ihe obu bu mmadu riwe ego n'izu a!

'What it means is that one should spend money this week!'

Speaker 1: O nke merenụ? Biko Chetakwa m.

'Was that what happened? Please remember me.'

Speaker 2: Ihe di $m$ mkpa ugbua bu $i$-change moto $m$.

'What is important to me now is changing my car.'

Speaker 1: Eziokwu! Inafelugo.

'Really! You have escaped.'

Armed with a prior knowledge of how the deal went, Speaker 1's responses were just to keep the conversation going and to hear more of Speaker 2's lies. Rather than confronting Speaker 2 openly, Speaker 1 chose to hide in ritual, pretending as if he was in agreement with what Speaker 2 was saying.

From these examples it would be seen that ritualized communication is communicatively important and can be assigned significance depending on the context. Whether sincerely or insincerely employed, its function seems to be to keep the conversation going. 


\section{Discussion}

From the few samples examined above, it could be seen that silence and ritual responses are important behavioural acts among the Igbos, and they are strategically employed in discourses to achieve specific communicative functions. Although these behavioural acts can be interchangeably used to perform certain functions in particular situations, say, in expressing neutrality or indifference, agreement, or even to avoid being one's real self in an attempt to escape from self-committing circumstances, silence can be used to perform all the other functions of ritual responses but the reverse is not generally the case. For example, silence can be comfortably used to avoid real and honest communication, to express surprise and wonder (as when someone is speechless with mouth agape), and even to express doubt and disbelief. However, it does seem that ritual responses cannot handle some of the communicative functions of silence, such as rejection, anger, or admission of guilt, without creating some ambiguities. It may be possible to employ ritual responses in fulfilling some of the above mentioned functions through the use of indirectness, but such usages will be highly restrictive and unexpected and may require special communicative ability to achieve the needed effects.

Thus, while silence can substitute for ritual responses, the latter cannot substitute for the former without generating serious discourse defects.

\section{Conclusion}

In this study, I have tried to show that silence and ritual responses are communicatively significant in Igbo discourse. They are behavioural acts that can be assigned significance in particular contexts in the on-going conversations.

This work should be seen as complementing Nwoye's article in Tannen and Saville-Troike [1985] by providing more contextual and real life discourse samples. By using actual examples, it becomes easier not only to identify the various uses of silence and ritual responses in specific contexts, but also to show how cultural and situational constraints can influence their communicative significance. I have tried to show that among the Igbos, silence can possibly be used to perform the same communicative functions as ritual responses, although the reverse is not the case in all situations. For example, whereas ritual responses are less likely to be used to communciate rejection, anger, or admission of guilt, they could be effectively used to communciate agreement, indifference or neutrality. The major specific function of ritualized communication seems to be an attempt to keep the conversation going, whether or not the actor's real intentions in doing so are genuine, a strategy that is not obvious with silence. However, since members of a particular culture are able to act and respond to these acts, interactants are always able to assign interpretations to them, even when such interpretations may differ from the actor's real intentions. 
It is hoped that this study will generate more interest in crosscultural study of these behavioural acts in real life situations for a better understanding of their functions in various cultures.

\section{REFERENCES}

Basso, Keith H. 1970. "To give up on words: silence in Western Apache culture." Southwestern Journal of Anthropology 26:213-230.

Butterworth, B. and G. Beatie. 1978. "Gesture and silence as indicators of planning in speech." In R.N. Campbell and Philip T. Smith (eds.), Recent Advances in the Psychology of Language, Vol. 46, pp. 347-360. New York and London: Plenum Press.

Gibb, J.R. 1961. "Defensive communication." Journal of Communication 11:141-148.

Goldman-Eisler, F. 1958. "Speech production and predictability of words in context and length of pauses in speech." Language and Speech 1:96-120.

Goldstein, D.E. 1987. Review of Perspectives on Silence. Language and Society 16:565-569.

Henderson, A., F. Goldman-Eisler and A. Skarbek. 1966. "Sequential temporal patterns in spontaneous speech." Language and Speech 9:207-216.

Nwoye, G.O. 1985. "Eloquent silence among the Igbo of Nigeria." In Deborah Tannen and Muriel Saville-Troike (eds.), Perspectives on Silence, pp. 185191. Norwood, NJ: Ablex Publishing Corporation.

Okolo, B.A. 1987. "Topic shading in an unplanned Igbo discourse." Studies in African Linguistics 18:211-237. 
Smith, R.D. and L.K. Williamson. 1977. Interpersonal Communication. Dubuque, Iowa: William C. Brown Company Publishers.

Tannen, Deborah and Muriel Saville-Troike (eds.). 1985. Perspectives on Silence. Norwood, NJ: Ablex Publishing Corporation.

Watzlawick, P., Janet H. Beavin and Don D. Jackson. 1967. Pragmatics of Human Communication: a Study of Interactional Patterns, Pathologies and Paradoxes. New York: W.W. Norton \& Co. 
